\title{
PREFACE
}

\section{Advances in targeted therapies VII}

F C Breedveld, J R Kalden, J S Smolen

$\mathrm{T}$ he papers brought together in this supplement of the Annals of the Rheumatic Diseases constitute summaries of presentations at the Seventh International Symposium on Advances in Targeted Therapies, which was held on 6-10 April 2005. As such these presentations represent the state of the art on the biology of mechanisms of action and pathophysiology of tumour necrosis factor (TNF) as well as other important mediators of inflammation. Current knowledge on the means and consequences of blocking TNF or other molecules or cellular mechanisms is presented as well.

We are grateful to Drs Crofford, Furst, Feldmann, Klareskog, Lipsky, Maini, Moreland, and Weinblatt, the members of the Advisory Board of the Symposium, for their invaluable help towards the success of the conference, the seventh of a series of similar events planned for the future. We particularly wish to thank all the speakers for their excellent presentations, most of which are summarised here in writing, and all the participants who actively contributed to the discussions. Finally, we also thank the sponsors* ${ }^{*}$ of this university driven event who have provided unrestricted educational grants that enabled us to invite the leading scientists in the field. Moreover, a rheumatological audience and the readers of this supplement have been able to obtain back to back information on the efficacy and safety of biological agents from representatives of the major companies involved with open discussion of issues arising regarding each agent when looked at individually and compared with others. It is also thankfully acknowledged that representatives of the FDA and EMEA actively participated in this symposium. Finally, based on the presentations and as a consequence of intensive discussions, a revised consensus statement on the application of TNF and interleukin (IL)-1 blocking agents in rheumatoid arthritis, psoriatic arthritis, and ankylosing spondylitis was formulated. We have to thank particularly Dr Furst for his guidance in this respect.

We hope that the readers of this supplement will enjoy the contributions as much as the participants seemed to enjoy the meeting.

*The conference was organised under the sole responsibility of the departments of the universities of Erlangen, Leiden, and Vienna in collaboration with an advisory board consisting of the above mentioned colleagues from departments of rheumatology of several American and European universities. The following companies provided unrestricted educational grants for the organisation of this conference: Abbott Immunology, Amgen, Bristol-Myers Squibb, Centocor, Genentech, Roche, Schering-Plough, UCB, and Wyeth. The pharmaceutical industry had no part in the decisions regarding the specific programme and, with the exception of few observers, participants were selected and solely invited by the organising committee. Several members of the advisory board and the members of the organising committee have obtained experience in the use of TNF and IL-1 blocking compounds in the course of their participation in clinical studies on TNF and IL-1 blocking agents (for which the costs were defrayed by industry). 